This item was submitted to Loughborough's Research Repository by the author.

Items in Figshare are protected by copyright, with all rights reserved, unless otherwise indicated.

\title{
Maturity-associated variance in physical activity and health-related quality of life in adolescent females: a mediated effects model
}

PLEASE CITE THE PUBLISHED VERSION

http://dx.doi.org/10.1123/jpah.9.1.86

\section{PUBLISHER}

(c) Human Kinetics

\section{VERSION}

SMUR (Submitted Manuscript Under Review)

\section{PUBLISHER STATEMENT}

This work is made available according to the conditions of the Creative Commons Attribution-NonCommercialNoDerivatives 4.0 International (CC BY-NC-ND 4.0) licence. Full details of this licence are available at: https://creativecommons.org/licenses/by-nc-nd/4.0/

\section{LICENCE}

CC BY-NC-ND 4.0

\section{REPOSITORY RECORD}

Smart, Joan E. Hunter, Sean P. Cumming, Lauren B. Sherar, Martyn Standage, Helen Neville, and Robert M. Malina. 2019. "Maturity-associated Variance in Physical Activity and Health-related Quality of Life in Adolescent Females: A Mediated Effects Model". figshare. https://hdl.handle.net/2134/22573. 
2 Maturity Associated Variance in Physical Activity and Health-Related Quality of Life in Adolescent Females: A Mediated Effects Model.

4

5

6

7

8

9

10

11

12

13

14

15

16

17

18

19

20 Key Words: Adolescence, Exercise, Physical Self-Concept

21 Abstract Word Count: 144

22 Manuscript Word Count: 4179

Submitted as Original Research 
Abstract

3 Background: This study tested a mediated effects model of psychological and behavioral

4 adaptation to puberty within the context of physical activity (PA).

5 Methods: Biological maturity status, physical self-concept, PA and health-related quality

6 of life (HRQoL) were assessed in 222 female British year 7-9 pupils (M age=12.7 years,

$7 \mathrm{SD}=.8)$

8 Results: Structural equation modeling using maximum likelihood estimation and boot-

9 strapping procedures supported the hypothesized model. Maturation status was inversely

10 related to perceptions of sport competence, body attractiveness, and physical condition;

11 and indirectly and inversely related to physical self-worth, PA and HRQoL. Examination

12 of the bootstrap-generated bias-corrected confidence intervals representing the direct and

13 indirect paths between suggested that physical self-concept partially mediated the

14 relations between maturity status and PA, and maturity status and HRQoL.

15 Conclusions: Evidence supports the contention that perceptions of the physical self

16 partially mediate relations maturity, PA, and HRQoL in adolescent females. 
1 Maturity Associated Variance in Physical Activity and Health-Related Quality of Life in

3 Physical activity (PA) plays an important role in the promotion and maintenance of

4 health. Individuals who regularly engage in moderate-to-vigorous bouts of PA

5 demonstrate improved functional capacity and are at less risk for many degenerative

6 diseases and psychological disorders (e.g., hypertension, type II diabetes, coronary heart

7 disease, depression and anxiety) ${ }^{1}$. PA is also considered a prerequisite for positive

8 physical and psychological development ${ }^{2}$. To ensure the health benefits afforded through

9 regular involvement in PA, children should be encouraged to be active from an early age.

10 However, evidence suggests that over the past four decades children are becoming less

11 active in many forms of PA, including physical education , active transport, and leisure-

12 time activities ${ }^{3}$.

13 Those involved in the study and promotion of PA in youth have generally

14 focussed on the roles that psychosocial and environmental factors play in relation to PA ${ }^{4}$.

15 Although factors, such factors undoubtedly contribute to children's involvement in PA, it

16 is increasingly evident that a true explanation of PA in youth resides in the independent

17 and interactive effects of various biological, psychosocial, and environmental factors ${ }^{5,6}$.

18 Accordingly, it has been suggested that researchers re-examine the biological basis of

19 PA with the intention of informing both theory and practice ${ }^{5-8}$. PA is, after all, a

20 biological process that exists within a complex cultural context in which value, meaning,

21 and sanctions are ascribed to it ${ }^{8}$.

22 A number of biological factors and processes have been identified as potential

23 contributors to variance in PA, including biological maturation ${ }^{6}$. Biological maturation 
1 refers to progression towards the mature (i.e., adult) state, can be considered in terms of

2 tempo and/or timing ${ }^{2}$, and may be particularly relevant to the study of PA in youth ${ }^{6}$.

3 Tempo refers to the rate at which maturation progresses, whereas timing refers to the time

4 at which certain maturity-related events occur (e.g., age-at-menarche or peak height

5 velocity). Children of the same chronological age can demonstrate considerable variation

6 in biological maturity, with some maturing much earlier or later than others.

$7 \quad$ There is good reason to believe that variance in biological maturation may

8 contribute to PA in adolescence, particularly in females. First, the observation that

9 individuals become less active as they progress towards the mature state is a consistent

10 finding in pediatric exercise science ${ }^{6}$. Second, evidence suggests that sex-related

11 variance in biological maturation explains differences in the PA of boys and girls of the

12 same chronological age ${ }^{9}$. Third, the physical characteristics associated with advanced

13 maturation in girls (i.e., greater pubertal gains in height, weight, and weight-for-height,

14 with gains in weight a result of increases in absolute and proportional fat-mass) may be

15 less conducive to successful involvement in $\mathrm{PA}^{7-8}$, especially in activities that emphasise

16 endurance, weight-bearing, and/or aesthetics. Finally, girls who are advanced in maturity

17 status are more likely to socialize with older, and less active, peer groups ${ }^{10}$.

18 In accordance with extant literature ${ }^{9}$, one would predict an inverse relation

19 between maturity status and PA in this adolescent females. Research examining this

20 contention has, however, produced equivocal results ${ }^{9}$. Whereas some studies have

21 shown late maturing females to be more active than early maturing females ${ }^{11,12}$, others

22 have found no relation between maturity status and PA ${ }^{13,14}$, or that early maturing girls

23 were more active ${ }^{15}$. Lack of consistency in these findings has been attributed to a number 
1 of factors, including a failure to address factors that may moderate or mediate relations

2 between maturation and PA, sample size, and construct measurement ${ }^{9}$. Whereas some

3 studies have relied on subjective measures of PA and maturation, others have employed a

4 combination of objective and subjective measures, or objective measures exclusively.

5 For a more comprehensive review and discussion of research pertaining to maturity

6 associated variance in PA see Sherar et al ${ }^{9}$.

$7 \quad$ In an attempt to explain relations between maturation status and PA in adolescent

8 girls, Cumming and colleagues ${ }^{16}$ proposed and tested a mediated effects model of

9 maturity associated variance in PA. The model, based on a Mediated Effects Model of

10 Psychological and Behavioural Adaptation to Puberty described by Petersen and Taylor

$11{ }^{17}$, hypothesized that relations between maturation status and PA were mediated by

12 physical self-concept (i.e., the feelings and beliefs that one has towards the physical self).

13 More specifically, it predicted that maturity status would be inversely related with

14 perceptions of physical self-concept, which would, in turn, positively predict involvement

15 in PA. Structural equation modelling employing bootstrapping procedures indicated

16 strong support for the model (CFI $=.95$; SRMR $=.08$ ) in a sample of adolescent British

17 female students aged 12-15 years. Early maturing girls held lower perceptions of body

18 attractiveness, sport competence, physical conditioning (but not strength) and overall

19 physical self-worth, which, in turn, predicted less involvement in PA. An indirect inverse

20 relation between maturation and PA was observed, through physical self-concept,

21 supporting the contention that physical self-concept mediates relations between the

22 aforementioned constructs. 
2 which to study and understand maturity associated variance in PA, it has, to date,

3 received limited empirical attention. Accordingly, the purpose of our investigation was to

4 test the aforementioned model on a separate sample and extend it to include a measure of

5 health-related quality of life (HRQoL) (Figure 1). There is good reason to believe that

6 maturation may be related to HRQoL in adolescent females. Due to greater gains in

7 absolute and proportional fat-mass, early maturing girls are more likely to be classified as

8 overweight or obese. Overweight and obese youth tend to report lower levels of HRQoL

9 when compared with their normal weight peers ${ }^{18-21}$. Early maturation also is associated

10 with a more negative body image and physical self-concept ${ }^{22}$ and less involvement in

11 health promoting activities such as exercise ${ }^{23}$ and competitive sports ${ }^{24}$. Early maturing

12 girls also report more negative initial experiences to puberty (e.g. inconvenience,

13 ambivalence and confusion; ${ }^{25}$ and increased distress, anxiety, depression, and

14 psychosomatic symptoms ${ }^{22,26-28}$. Early maturity is also linked with early substance abuse $15{ }^{29}$, alcohol abuse ${ }^{30}$ and early sexual initiation ${ }^{31}$.

16 In accordance with extant literature pertaining to maturation, PA and health in

17 adolescent girls ${ }^{2,13,32}$, the hypothesized mediated effects model (Figure 1) predicted that

18 (i) advanced maturation would predict lower perceptions of sport competence, body

19 attractiveness and physical condition, but higher perceptions of strength; (ii) that

20 perceptions of sport competence, body attractiveness, physical condition and strength

21 would, in turn, positively predict physical self-worth; (iii) that physical self-worth would

22 positively predict involvement in PA; (iv) that PA and would positively predict HRQoL

23 (v) that biological maturity status would indirectly predict variance in both physical self- 
1 worth, PA, and HRQoL; (vi) and that physical self-worth would directly and indirectly

2 (via PA) predict HRQoL.

$4 \quad$ Participants

5 Participants were 222 female Year 7 through 9 pupils from a single-sex state

6 funded school in the South West of England $(M$ age $=12.7, S D=.8$ years; range $=10-14$

7 years). The study was approved by the School for Health’s research ethics committee.

8 Written consent was obtained from the Head Teacher, who acted in loco parentis. Parents

9 were informed of the research by post and asked to provide passive consent (i.e., contact

10 the school/researchers if they did not wish their child to take part). Verbal consent was

11 obtained from pupils.

12 Field Protocol

13 Prior to the start of a Physical Education class, participants completed a series of 14 self-report questionnaires, including the Physical Activity Questionnaire for Adolescents

15 (PAQ-A) ${ }^{33}$, the Children and Youth's Physical Self-Perceptions Scale (CY-PSPP) ${ }^{34}$, and

16 the Kidscreen-10 HRQoL Questionnaire (K-10). Height and weight were measured using

17 standardized procedures ${ }^{35}$. Chronological age in decimals was calculated as the

18 difference between date of birth and date of measurement.

19 Measures

20 Estimated Maturity Status. Percentage of predicted mature (adult) height attained

21 at the time of measurement was used as a non-invasive estimate of biological maturity

22 status. This method assumes that among youth of the same chronological age, the child

23 who is closer to his/her predicted mature height is biologically older (i.e., more advanced 
1 in maturity) than the individual who is further removed from his/her predicted adult

2 height than expected for age ${ }^{2}$. For example, the mean percentage of mature height

3 attained in girls of the Berkeley Guidance Study at the age of 12 years is $93 \%{ }^{36}$. A girl

4 who has attained $98 \%$ of her predicted adult height at 12 years would be considered

5 biologically older than a girl of the same chronological age who has attained $86 \%$ of her

6 predicted adult height.

$7 \quad$ The Khamis-Roche method ${ }^{37}$ was used to predict the mature height from current

8 age, height and weight of the participant and midparent height (average height of

9 biological parents). The median error bound (median absolute deviation) between actual

10 and predicted mature height at 18 years of age is $2.2 \mathrm{~cm}$ in males and $1.7 \mathrm{~cm}$ in females

$11 \quad 37$. Biological parents of the participants reported their heights. As adults generally

12 overestimate height, the self-reported height of each parent was adjusted for over

13 estimation using an equation constructed from over 1000 measured and estimated heights

14 of adults ${ }^{38}$.

15 Estimated biological maturity status was expressed as a $z$-score, using the

16 percentage of predicted adult height attained at the time of measurement, and half-year

17 age- and sex-specific means and standard deviations from the Berkeley Guidance Study

$18{ }^{36}$. The reference sample was selected on four counts: first, mean heights and weights of

19 boys and girls aged 13-15 years in the guidance sample are similar to current United

20 Kingdom reference values ${ }^{39}$; second means and standard deviations in the guidance

21 sample are reported at half year intervals; third, the Khamis-Roche method for predicting

22 adult height uses the same half-year age intervals as the Guidance study sample; fourth,

23 the mean percentages of predicted adult height attained at all whole years (e.g., 11.0 
1 years, 12.0 years) are very similar to those in a more recent sample ${ }^{37}$. The Khamis-Roche

2 method for estimating biological maturation has been used in a number of studies with

3 US and British youth ${ }^{40-43}$ and has been validated against established indicators of

4 maturity (skeletal age) in youth American football players ${ }^{44}$.

5 Physical Activity. The Physical Activity Questionnaire for Adolescents (PAQ-A)

$6 \quad{ }^{33}$ was used to assesses involvement in PA. The PAQ-A is an eight item instrument that

7 requires participants to indicate how frequently they engaged in various activities over a

8 seven day recall period. The PAQ-A has demonstrated adequate levels of validity and

9 reliability ${ }^{45}$. In the current sample the PAQ-A demonstrated an acceptable level of

10 internal consistency (Cronbach’s alpha $=.79$ ).

11 Physical Self-Concept. The Children and Youths’ Physical Self-Perception Profile

12 (CY-PSPP) ${ }^{34}$ was used to assess the physical self-concept. This scale assesses 6

13 dimensions of the self (i.e., sport competence, physical condition, body attractiveness,

14 strength, physical self-worth, and general self-worth) and requires participants to

15 responds to a series of 36 items that are structured in an alternative response format

16 Theoretically, the physical self-worth dimension is considered a higher-order construct,

17 with sport competence, physical condition, body attractiveness, and strength serving as

18 lower-order constructs that contribute to physical self-worth. All dimensions of the CY-

19 PSPP, with the exception of general self-worth were included in the current analyses. The

20 CY-PSPP has previously demonstrated acceptable levels of construct validity and

21 reliability ${ }^{46}$. All dimensions of the CY-PSPP used in the current study demonstrated

22 adequate levels of internal consistency (Cronbach’s alphas ranged from .89-.93). 
2 HRQoL Questionnaire (K-10). The inventory contains ten items comprising

3 psychological, physical and social dimensions of HRQoL. Based on a one-week recall

4 period, pupils estimated the intensity of their feelings towards each item using a five-

5 point Likert scale. Rasch scores were calculated, after the reversal of negatively

6 formulated items, and converted into t-values with a scale mean of 50 and a standard

7 deviation of 10, based on data from the Kidscreen international survey sample (The

8 Kidscreen Group, 2006). Higher scores reflect superior HRQoL. Good test re-test

9 reliability $(r=0.73$; ICC $=0.72)$ and high convergent validity with other generic HRQoL

10 instruments, including the Youth Quality of Life Instrument-Surveillance Version ( $r=$

11 0.61), was supported by The Kidscreen Group (2006). Acceptable internal consistency

12 was exhibited in the current sample (Cronbach’s $\alpha=.79$ ).

13 Statistical Analyses

14 Descriptive statistics by age group were calculated for body size, percentage of predicted

15 mature height, maturity status, physical self-concept, PA, and HRQoL. Pearson product

16 moment correlations (one-tailed) were calculated to examine relations among the

17 variables of interest. Structural equation modeling, utilizing maximum likelihood

18 estimation and bootstrapping procedures, was used to test the hypothesized model

19 concerning relations among maturational status, physical self-concept, PA, and HRQoL.

20 To determine the adequacy of model fit, a 2-index presentation strategy advanced by $\mathrm{Hu}$

21 and Bentler ${ }^{47}$ was employed. This strategy uses the Standardized Root Mean Square

22 Residual (SRMR) and incremental or absolute indexes of fit (e.g., Comparative Fit Index

23 -CFI). SRMR values close to .08 (or lower) are indicative of a well-specified model ${ }^{47}$ 
1 whereas CFI values of over .90 and .95 reflect acceptable and excellent fit between the

2 model and data, respectively ${ }^{47}$. In accordance with recent recommendations ${ }^{48}$, mediated

3 effects were explored by examining the $90 \%$ upper and lower limits of bootstrap-

4 generated bias-corrected confidence intervals (BBC CI) of indirect effects.

5

6

13 age group. Mean values for weight and BMI fell between the $50^{\text {th }}$ and $75^{\text {th }}$ centiles at age

1412 and 14 , yet approximated the $75^{\text {th }}$ centile at 11 and 13 years. Mean values for BMI

15 approximated or fell just below the $75^{\text {th }}$ centile in all age groups. Mean values for

16 HRQoL fell below the International Standard in all age groups.

\section{Correlations}

19 HRQoL are presented in Table 2. As predicted, estimated biological maturity status was

20 negatively associated with sport competence, physical condition, body attractiveness,

21 physical self-worth, PA, and HRQoL. Though positive, the relation between maturation

22 status and strength was non-significant. PA was positively associated with HRQoL and

23 all dimensions of the CY-PSPP.

24 The Mediated Effects Model 
1 Given the complexity of the hypothesized model, a parceling strategy ${ }^{49}$ was

2 employed to limit the number of estimated parameters. The six items of each subscale of

3 the CY-PSPP were parceled into three indicators of a latent variable that reflected the

4 subscale. The three items with the highest item-to-construct loadings were used to anchor

5 each of the three indicators. The three items with the next highest loadings were then

6 added to the anchors in reverse order (e.g., $1^{\text {st }} \& 6^{\text {th }}, 2^{\text {nd }} \& 5^{\text {th }}, \& 3^{\text {rd }} \& 4^{\text {th }}$, highest

7 loading items parcelled together), thus increasing the likelihood that parcels were

8 balanced in terms of difficulty and discrimination and limiting experimenter bias ${ }^{49}$. The

9 sum of the two items was used to create each indicator of the latent variable (i.e. parceled

10 item). Using the same procedures, the eight items representing the PAQ-A were parceled

11 into four indicators of a latent variable that reflected PA. Similarly, the ten items

12 representing HRQoL were parceled into five indicators of a latent variable that

13 represented that construct. For a more in-depth explanation of parceling process and its

14 advantages see the review by Little and colleagues ${ }^{49}$.

15 In light of the moderate-to-strong correlations among the sub-dimensions of the

16 CY-PSPP, covariance paths between the disturbance terms of the latent factors (i.e., sport

17 competence, physical condition, body attractiveness, strength) were added to the

18 hypothesized model. These paths specify the interrelations between the various sub-

19 dimensions and the shared variance not accounted for by the predictor variable.

20 Employing AMOS 16.0 software, structural equation modelling (SEM) using

21 maximum likelihood estimation was used to test the fit of the hypothesized model.

22 Inspection of the Mardia's Coefficient value $(63.46, p<.001)$ revealed the data to depart

23 from multivariate normality. Thus, the SEM analysis was conducted using the 
1 bootstrapping procedure with 5000 bootstrap replication samples to provide a more

2 accurate assessment of the parameter estimates' stability ${ }^{50}$.

3 The model fit indices suggested a good fit between the proposed model and the

4 data (SRMR $=.07$; CFI =.95).The standardized Beta coefficients, standard errors, and

5 squared multiple correlations (SMC) associated with the model are presented in Figure 2.

6 As predicted, biological maturity status negatively predicted perceptions of sport

7 competence $(\beta=-.19, \mathrm{p}<.01)$, physical condition $(\beta=-.29, \mathrm{p}<.001)$ and body attractiveness

$8 \quad(\beta=-.35, \mathrm{p}<.001)$. Maturity status was, however, unrelated to perceived strength.

9 Perceptions of sport competence $(\beta=.39, \mathrm{p}<.01)$ and body attractiveness $(\beta=.58, \mathrm{p}<.001)$,

10 but not physical condition or strength, predicted physical self-worth. In turn, physical

11 self-worth positively predicted involvement in PA $(\beta=.50, \mathrm{p}<.001)$ and HRQoL $(\beta=.67$,

$12 \mathrm{p}<.001)$. Contrary to expectations, PA was unrelated to HRQoL. Finally, maturity status

13 was found to be indirectly related to physical self-worth ( $\beta=-.28(90 \% \mathrm{CI} \pm .11$ ),

$14 \mathrm{p}<.001)$, PA $(\beta=-.14(90 \% \mathrm{CI} \pm .08), \mathrm{p}<.001)$, and HRQoL $(\beta=-.17(90 \% \mathrm{CI} \pm .08)$,

$15 \mathrm{p}<.001)$. An indirect relation between physical self-worth and HRQoL was not observed

$16 \quad(\beta=-.06(90 \% \mathrm{CI} \pm .12), \mathrm{p}>.05$

17 A version of Baron and Kenny's method for testing meditational hypotheses ${ }^{51}$

18 adapted for structural equation modelling ${ }^{52}$ was employed to test for mediation in the

19 indirect effects. Accordingly, bootstrap-generated bias-corrected confidence intervals

20 were used to estimate the standardized path coefficients representing the direct effects,

21 with and without the inclusion of the mediating variables. Without the mediating

22 variables the direct path coefficients between maturity and physical self-worth $(\beta=-.26$

$23(\mathrm{BBC} 90 \% \mathrm{CI}=-.38,-.14), \mathrm{p}<.001)$, and maturity and $\mathrm{PA}(\beta=-.19(\mathrm{BBC} 90 \% \mathrm{CI}=-.33$, 
$1-.06), \mathrm{p}<.01)$, and maturity and HRQoL $(\beta=-.15$ (BBC 90\% CI = -.30, .00), $\mathrm{p}=.05$ ) were

2 negative and significant. However, when the mediating variables were included in the

3 model the path coefficients representing the direct effects between maturity and physical

4 self-worth $(\beta=.04(\mathrm{BBC} 90 \% \mathrm{CI}=-.06, .14), \mathrm{p}=.39)$, maturity and $\mathrm{PA}(\beta=-.07$ (BBC

$590 \% \mathrm{CI}=-.15, .07), \mathrm{p}=.32)$, and maturity and HRQoL $(\beta=.00(\mathrm{BBC} 90 \% \mathrm{CI}=-.15, .15)$,

$6 \mathrm{p}=.99)$ were all attenuated and non-significant. Collectively, these results suggest that the

7 indirect effect between maturity and physical HRQoL was fully mediated, and that the

8 indirect effects between maturity and physical self-worth, and maturity and PA were

9 partially mediated. ${ }^{1}$ Inspection of the modification indices and standardized residuals

10 associated with the hypothesized models did not indicative any improvements to the

11 model that were theoretically or substantively justified.

\section{Discussion}

13 The results of this study provide partial support for the hypothesized mediated

14 effects model and the contention that advanced maturation in adolescent girls is

15 associated with less involvement in PA ${ }^{11,12}$. Specifically, physical self-concept was

16 found to partially mediate an inverse relation between maturity status and PA. The

17 magnitude and direction of the path coefficients in the hypothesized model were

18 consistent with those described in the mediated effects model presented by Cumming and

19 colleagues ${ }^{16}$. Advanced maturation was associated with lower perceptions of body

20 attractiveness, physical condition and sport competence, though no relation was observed

21 with perceived strength. Perceptions of body attractiveness and sport competence, but

\footnotetext{
${ }^{1}$ At the request of a reviewer, a model specifying direct paths from a potential covariate (viz., chronological age) was analyzed to examine any potential effects of this variable on the paths shown in Figure 2. The direct and indirect path coefficients remained significant, indicating that they did not differ as a function of chronological age.
} 
1 not strength or physical condition, served as positive predictors of physical self-worth

2 which, in turn, predicted greater involvement in PA.

3 The current model advanced the original model ${ }^{16}$ by including HRQoL as

4 endogenous latent variable. As predicted, HRQoL was found to be positively related

5 physical self-worth and indirectly and inversely related to maturity status. Physical self-

6 concept and PA were found to fully mediate the inverse relation between maturation

7 status and HRQoL, further highlighting the potential role that perceptions of the self and

8 PA may play in explaining relations between maturation status and HRQoL in adolescent

9 females. Future research should explore the independent and interactive effects of

10 maturation, physical self-concept and PA in relation to a wider range of health outcomes

11 (e.g., smoking, drinking, diet, sexual behavior). Contrary to expectations, PA was found

12 to be unrelated to HRQoL. This result was somewhat surprising, as previous research has

13 reported positive relations between these constructs ${ }^{53}$.

14 The comparatively strong relations among maturation, body attractiveness, and

15 physical self-worth are worthy of discussion. Maturity-associated changes in physical

16 appearance (e.g., body size, composition, physique, development of secondary sex

17 characteristics) may be of greater importance to adolescent females than changes in

18 functional capacity (e.g., sport competence, physical condition, strength). (9). Physical

19 appearance is recognized as the most salient source of self-worth and esteem in

20 adolescent girls ${ }^{54}$. A qualitative study of over 50 US adolescent girls and boys revealed

21 that the subject of body attractiveness dominated girls conversations during adolescence

22 and was considered to be of greater importance than accomplishments in achievement 
1 domains such as education and sports ${ }^{55}$. Strength and physical condition may also be

2 less salient as sources of self-worth among adolescent females than they are in males ${ }^{56}$.

3 The mediated effects model described by Petersen and Taylor ${ }^{17}$ presents an

4 appealing multidisciplinary framework through which maturity-associated variation in

5 health related behaviors can be studied. The model also affords an ideal framework from

6 which to examine the potential influence of social and environmental factors. For

7 example, the degree to which maturation and physical self-concept impact involvement in

8 PA, might be moderated by social support (e.g., peer or parental), cultural ideals, or the

9 availability of activity related resources (i.e., parks, leisure centers). Although the impact

10 of moderating factors was not examined in the current study, future researchers should

11 seek to explore and validate this aspect of Petersen and Taylor's model ${ }^{17}$.

12 From a practical perspective, Petersen and Taylor's ${ }^{17}$ model identifies a means

13 through which maturity associated declines in PA and HRQoL might be countered (i.e.,

14 physical self-concept, social support). A lack of subjective and cognitive knowledge with

15 regards to the female body and the processes of growth and maturation has been

16 documented as a source of anxiety in adolescent girls ${ }^{55}$. Interventions designed to

17 educate students on the processes of growth and maturation, and/or encourage them to

18 view puberty as a normal and attractive consequence of becoming an adult, may help

19 students adapt more positively to pubertal changes in health and behavior. Such

20 interventions would undoubtedly require a combination of education and the personal

21 reorganization and reinterpretation of body image and related self-concepts, and might

22 mirror or develop from existing interventions such as Cash's body-image Cognitive

23 Behavioral Therapy (CBT) program ${ }^{57}$. Although there is much evidence that body-image 


\section{MATURATION, PHYSICAL SELF, PHYSICAL ACTIVITY}

1 CBT programs are effective in collegiate and adult samples, there is a paucity of literature

2 examining the efficacy of such interventions in adolescents ${ }^{58}$. Most interventions seeking

3 to promote positive change in adolescents’ physical self-concept have limited their

4 strategies to the promotion of exercise (Fox, 2000). Though greater involvement in

5 exercise can undoubtedly enhance physical self-concept, such interventions are limited in

6 that they do not challenge the beliefs and perceptions that underpin physical self-concept.

7 It is important to recognize a number of limitations associated with the current

8 study. First, the results are limited to adolescent girls living in the Southwest of England.

9 Relations among the variables of interest might vary with age, social circumstance, and

10 culture. For example, body attractiveness is considered a more salient source of self-

11 worth in working class girls ${ }^{55}$, and African American girls tend to be more satisfied with

12 their bodies than white girls ${ }^{59}$. Second, inferences regarding cause and effect relations

13 cannot be made due to the study's cross-sectional design. To obtain more precise

14 information about how physical self-perceptions might mediate relations between

15 maturation and PA it, longitudinal research is required, ideally beginning in late

16 childhood and tracking changes through to late adolescence. Third, the method for

17 estimating maturity status was derived from data collected in the United States. British

18 and American boys and girls aged 9-15 years present very similar mean heights and

19 weights ${ }^{60}$ (http://www.cdc.gov/growthcharts), however, further research is required to

20 validate the formulae in British samples. Although mean estimates of maturity status

21 were generally 'on-time', the mean values suggested a slight delay in maturity status in

22 the oldest age group. This may reflect the relatively smaller group sizes or a tendency for

23 older early maturing girls to opt out of studies that require measurements of weight. 
1 Finally, self-report measures of PA rely on the participant's memory to assess activity

2 levels and can potentially be influenced by socially desirability. Despite these limitations,

3 the PAQ-A is considered a valid, low cost, and easy to use measures of activity that is

4 well suited for use within youth ${ }^{33,45}$.

5 In summary, this study supports the mediated effects of model of maturity

6 associated variation in $\mathrm{PA}^{16}$ and the contentions that advanced maturation in adolescent

7 females is associated with less involvement and PA and lower HRQoL. Accordingly,

8 researchers PA and HRQoL in youth would do well to consider the contribution of

9 biological maturity status and its potential role as a confounding and/or masking

10 variable $^{61}$.

11 
2 1. Department of Health Physical Activity Health Improvement and Prevention. At least five a week: Evidence on the impact of physical activity and its relationship to health. London: Department of Health; 2004.

2. Malina R. M., Bouchard C., Bar-Or O. Growth maturation and physical activity. Champaign, IL: Human Kinetics 2004.

3. Malina R. M., Katzmarzyk P. T. Physical activity and fitness in an international growth standard for preadolescent and adolescent children. Food and Nutrition Bulletin. Dec 2006;27:S295-S313.

4. Cumming S. P., Riddoch C. Physical activity, physical fitness, and health: Current concepts. In: Armstrong N, Van Mechelen W, eds. Paediatric exercise science and medicine: Oxford University Press; 2009:327-338.

5. Rowland T. W. The biological basis of physical activity. Medicine and Science in Sports and Exercise. 1998;30:392-399.

6. Eisenmann J. C., Wickel E. E. Biology of physical activity in children: Revisited. Pediatric Exercise Science. 2009;21:257-272.

7. Katzmarzyk P. T., Baur L. A., Blair S. N., et al. International conference on physical activity and obesity in children: Summary statement and recommendations. International Journal of Pediatric Obesity. 2008;1:1-19.

8. Malina R. M. Biocultural factors in developing physical activity levels. In: Smith AL, Biddle SJH, eds. Youth physical activity and inactivity. Champaign, Ill.: Human Kinetics; 2008:141-166.

9. Sherar L. B., Cumming S. P., Eisenmann J. C., et al. Adolescent biological maturity and physical activity: Biology meets behaviour Pediatric Exercise Science. in press.

10. Caspi A., Moffitt T. E. Individual differences are accentuated during periods of social change: The sample case of girls at puberty. Journal of Personality and Social Psychology. 1991;61:157-168.

11. Riddoch C., Mattocks C., Deere K., et al. Objective measurement of levels and patterns of physical activity. Archives of Disease in Childhood. 2007;92:963-969.

12. Davison K. K., Werder J. L., Trost S. G., et al. Why are early maturing girls less active? Links between pubertal development, psychological well-being, and physical activity among girls at ages 11 and 13. Social Science and Medicine. 2007;64:2391-2404.

13. Niven A. G., Fawkner S. G., Knowles A., et al. Maturational differences in physical self-perceptions and the relationship with physical activity in early adolescent girls. Pediatric Exercise Science. 2007;19:472-480.

14. Wickel E. E., Eisenmann J. C. Maturity-related differences in physical activity among 13-14- year old adolescents. Pediatric Exercise Science. 2007;19:384-392.

15. van Jaarsveld C. H. M., Fidler J. A., Simon A. E., et al. Persistent impact of pubertal timing on trends in smoking, food choice, activity, and stress in adolescence. Psychosomatic Medicine. Oct 2007;69:798-806.

16. Cumming S. P., Standage M., Loney T., et al. The mediation effect of physical self-concept on relations between biological maturity status and physical activity in adolescent females. Journal of Adolescence. in press. 
17. Petersen A. C., Taylor B. The biological approach to adolescence: Biological change and psychological adaptation. In: Adelson J, ed. Handbook of adolescent psychology. New York: Wiley-Interscience; 1980:117-155.

18. Friedlander S. L., Larkin E. K., Rosen C. L., et al. Decreased quality of life associated with obesity in school-aged children. Archives of Pediatrics \& Adolescent Medicine. Dec 2003;157:1206-1211.

19. Schwimmer J. B., Burwinkle T. M., Varni J. W. Health-related quality of life of severely obese children and adolescents. Journal of the American Medical Association. Apr 9 2003;289:1813-1819.

20. Swallen K. C., Reither E. N., Haas S. A., et al. Overweight, obesity, and healthrelated quality of life among adolescents: The national longitudinal study of adolescent health. Pediatrics. Feb 2005;115:340-347.

21. Williams J., Wake M., Hesketh K., et al. Health-related quality of life of overweight and obese children. Journal of the American Medical Association. 2005;293:70-76.

22. Graber J. A., Brooks-Gunn J., Warren M. P. The vulnerable transition: Puberty and the development of eating pathology and negative mood. Womens Health Issues. 1999;9:107-114.

23. Cumming S. P., Standage M., Gillison F., et al. Sex differences in exercise behavior during adolescence: Is biological maturation a confounding factor? Journal of Adolescent Health. May 2008;42:480-485.

24. Malina R. M. The young athlete: Biological growth and maturation in a biocultural context. In: Smoll FL, Smith RE, eds. Children and youth in sport: A biopsychosocial perspective. 2nd ed. Dubuque, IA: Kendall/Hunt; 2002:261-292.

25. Ruble D. N., Brooks-Gunn J. The experience of menarche. Child Dev. 1982;53:1557-1566.

26. Kaltiala-Heino R., Kosunen E., Rimpela M. Pubertal timing, sexual behaviour and self-reported depression in middle adolescence. Journal of Adolescence. Oct 2003;26:531-545.

27. Kaltiala-Heino R., Marttunen M., Rantanen P., et al. Early puberty is associated with mental health problems in middle adolescence. Soc.Sci Med. 2003;57:10551064.

28. Laitinen-Krispijn S., Van der E. J., Hazebroek-Kampschreur A. A., et al. Pubertal maturation and the development of behavioural and emotional problems in early adolescence. Acta Psychiatr Scand. 1999;99:16-25.

29. Dick D. M., Rose R. J., Viken R. J., et al. Pubertal timing and substance use: Associations between and within families across late adolescence. Dev.Psychol. 2000;36:180-189.

30. Costello E. J., Sung M., Worthman C., et al. Pubertal maturation and the development of alcohol use and abuse. Drug Alcohol Depend. 2007;88 Suppl 1:S50-9. Epub;\%2007 Feb 1.:S50-S59.

31. Brown J. D., Halpern C. T., L'Engle K. L. Mass media as a sexual super peer for early maturing girls. J Adolesc.Health. 2005;36:420-427.

32. Davison K. K., Werder J. L., Trost S. G., et al. Why are early maturing girls less active? Links between pubertal development, psychological well-being, and 
physical activity among girls at ages 11 and 13. Social Science and Medicine. 2007;64:2391-2404.

33. Kowalski K. C., Crocker P. R. E., Donen R. M. The physical activity questionnaire for older children (paq-c) and adolescents (paq-a) manual.2004, University of Saskatchewan, Saskatoon, CA.

34. Whitehead J. R. A study of children's physical self-perceptions using an adapted physical self-perception profile questionnaire. Pediatric Exercise Science. 1995;7:132-150.

35. Malina R. M. Anthropometry. In: P.J. M, Foster C, eds. Physiological assessment of human fitness 1995:205-219.

36. Bayer L. M., Bayley N. Growth diagnosis: Selected methods for interpreting and predicting development from one year to maturity. Chicago: University of Chicago Press; 1959.

37. Khamis H. J., Roche A. F. Predicting adult height without using skeletal age: The khamis-roche method. Pediatrics. 1994;94:504-507 (Pediatrics, 595, 457, 1995 for the corrected version of the tables).

38. Epstein L., Valoski A. M., Kalarchian M. A., et al. Do children lose and maintain weight easier than adults? A comparison of child and parent weight changes from six months to ten years. Obesity Research. 1995;3:411-417.

39. Freeman J. V., Cole T. J., Chinn S., et al. Cross-sectional stature and weight reference curves for the uk. Archives of Disease in Childhood. 1995;73:17-24.

40. Malina R. M., Morano P. J., Barron M., et al. Growth status and estimated growth rate of youth football players: A community-based study. Clinical Journal of Sport Medicine. May 2005;15:125-132.

41. Cumming S. P., Battista R. A., Standage M., et al. Estimated maturity status and perceptions of adult autonomy support in youth soccer players. Journal of Sports Sciences. Oct 2006;24:1039-1046.

42. Malina R. M., Morano P. J., Barron M. A., et al. Incidence and player risk factors for iinjury in youth football. Clinical Journal of Sports Medicine. 2006;3:214-222.

43. Sweet S. L., Dompier T. P., Stoneberg K. N., et al. Self-reported parent stature is acceptable in estimates of maturity status in youth soccer players. Journal of Athletic Training. 2002;4:S-129.

44. Malina R. M., Dompier T. P., Powell J. W., et al. Validation of a noninvasive maturity estimate relative to skeletal age in youth football players. Clinical Journal of Sport Medicine. Sep 2007;17:362-368.

45. Kowalski K. C., Crocker P. R. E., Kowalski N. P. Convergent validity of the physical activity questionnaire for adolescents. Pediatric Exercise Science. 1997;9:342-352.

46. Eklund R. C., Whitehead J. R., Welk G. J. Validity of the children and youth physical self-perception profile: A confirmatory factor analysis. Research Quarterly for Exercise and Sport. Sep 1997;68:249-256.

47. Hu L., Bentler P. Cut off criteria for fit indexes in covariance structure analysis: Conventional criteria versus new alternatives. Structural Equation Modeling. 1999;6:1-55. 
48. MacKinnon D. P., Lockwood C. M., Williams J. Confidence limits for the indirect effect: Distribution of the product and resampling methods. Multivariate Behavioral Research. 2004;39:99-128.

49. Little T. D., Cunningham W. A., Shahar G., et al. To parcel or not to parcel: Exploring the question, weighing the merits. Structural Equation Modeling. 2002;9:151-173.

50. Byrne B. Structural equation modeling with amos: Basic concepts, applications, and programming. Mahwah, NJ: LEA; 2001.

51. Baron R. M., Kenny D. A. The moderator-mediator variable distinction in social psychological research: Conceptual, strategic and statistical considerations. Journal of Personality and Social Psychology. 1986;51:1173-1182.

52. Shrout P. E., Bolger N. Mediation in experimental and nonexperimental studies: New procedures and recommendations. Psychological Methods. 2002;7:422-445.

53. Vuillemin A., Boini S., Bertrais S., et al. Leisure time physical activity and health-related quality of life Preventive Medicine. 2005;41:562-569.

54. Page A., Fox K. Adolescent weight-management and the physical self. In: Fox K, ed. The physical self: From motivation to well-being. Champaign, IL.: Human Kinetics; 1997:229-256.

55. Martin K. A. Puberty, sexuality, and the self: Girls and boys at adolescence. New York: Routledge; 1996.

56. Cover-Jones M. A study of socialization patterns at the high school level. Journal of Genetic Psychology. 1958;93:87-111.

57. Cash T. F. The body-image workbook: An eight step program for learning to like your looks. Oakland, CA: New Harbinger; 1997.

58. Cash T. F., Strachan M. D. Cognitive-behavioral approaches to changing body image. In: Cash TF, Pruzinsky T, eds. Body image: A handbook of theory, research, and clinical practice. New York, NY: Guilford Press; 2002:478-486.

59. Parker S., Nichter M., Nichter M., et al. Body-image and weight concerns among african-american and white adolescent females - differences that make a difference. Human Organization. Sum 1995;54:103-114.

60. Cole T. J. Growth charts for both cross-sectional and longitudinal data. Statistics in Medicine. Dec 30 1994;13:2477-2492.

61. Baxter-Jones A. D. G., Eisenmann J. C., Sherar L. B. Controlling for maturation in pediatric exercise science. Pediatric Exercise Science. Feb 2005;17:18-30. 
1 Table 1. Descriptive statistics for chronological age, estimated biological maturity status,

2 physical self-perceptions, and physical activity of adolescent British female pupils by age

3 group.

4

\begin{tabular}{|c|c|c|c|c|}
\hline & $\begin{array}{l}\text { 11years* } \\
n=54\end{array}$ & $\begin{array}{l}\text { 12years } \\
n=88\end{array}$ & $\begin{array}{l}\text { 13years } \\
\qquad \mathrm{n}=60\end{array}$ & $\begin{array}{l}\text { 14years } \\
n=20\end{array}$ \\
\hline Chronological age & $11.59(.2)$ & $12.47(.3)$ & $13.39(.3)$ & $14.11(.1)$ \\
\hline Maturity status z-score & $-.13(.87)$ & $-.29(.92)$ & $.07(.87)$ & $-.43(.70)$ \\
\hline Height (cm) & $151.9(7.5)$ & $155.0(6.6)$ & $161.8(6.2)$ & $163.1(6.3)$ \\
\hline Weight (kg) & $43.6(8.5)$ & $46.7(8.6)$ & $55.3(9.6)$ & $54.2(6.5)$ \\
\hline BMI $\left(\mathrm{kg} / \mathrm{m}^{2}\right)$ & $18.8(2.6)$ & $19.3(2.8)$ & $21.1(3.2)$ & $20.3(1.9)$ \\
\hline Sport competence & $2.57(.71)$ & $2.65(.61)$ & $2.56(.65)$ & $2.64(.74)$ \\
\hline Physical condition & $2.69(.70)$ & $2.87(.58)$ & $2.69(.72)$ & $2.81(.77)$ \\
\hline Body attractiveness & $2.54(.62)$ & 2.54 (.69) & $2.37(.74)$ & $2.47(.65)$ \\
\hline Physical strength & $2.58(.58)$ & $2.58(.51)$ & $2.55(.60)$ & $2.38(.48)$ \\
\hline Physical self-worth & $2.68(.70)$ & $2.72(.67)$ & $2.61(.68)$ & $2.62(.73)$ \\
\hline Physical activity & $2.67(.64)$ & $2.54(.56)$ & $2.59(.69)$ & $2.71(.66)$ \\
\hline Health-related quality of life & $47.0(7.8)$ & $45.5(7.2)$ & $46.0(7.3)$ & $44.9(6.5)$ \\
\hline $\begin{array}{l}\text { Percentage of predicted } \\
\text { adult stature attained }\end{array}$ & $90.9(2.9)$ & $93.6(2.7)$ & $97.0(1.9)$ & $97.7(.9)$ \\
\hline
\end{tabular}


Table 2. Pearson product moment correlations (one-tailed) between measures of estimated biological maturity status, physical selfconcept, physical activity, and health-related quality of life.

\begin{tabular}{|c|c|c|c|c|c|c|c|}
\hline & 1 & 2 & 3 & 4 & 5 & 6 & 7 \\
\hline \multicolumn{8}{|l|}{ 1. Biological maturity status } \\
\hline 2. Sport competence & $-.18 * *$ & & & & & & \\
\hline 3. Physical condition & $-.27 * * *$ & $.82 * * *$ & & & & & \\
\hline 4. Body attractiveness & $-.34 * * *$ & $.61 * * *$ & $.61 * * *$ & & & & \\
\hline 5. Physical strength & .10 & $.55 * * *$ & $.48 * * *$ & $.38 * * *$ & & & \\
\hline 6. Physical self-worth & $-.25 * * *$ & $.76 * * *$ & $.74 * * *$ & $.83 * * *$ & $.51 * * *$ & & \\
\hline 7. Physical activity & $-.18 * *$ & $.51 * * *$ & $.52 * * *$ & $.33 * * *$ & $.40 * * *$ & $.43 * * *$ & \\
\hline 8. Health-related quality of life & $-.12 *$ & $.43 * * *$ & $.38 * * *$ & $.42 * * *$ & $.26 * * *$ & $.52 * * *$ & $.21 * *$ \\
\hline
\end{tabular}

$*=\mathrm{p}<.05 ; * *=\mathrm{p}<.01 ; * * *=\mathrm{p}<.001$ 
Figure 1. Hypothesized mediated effects model describing relations among biological maturity status, physical self-concept, physical activity and health-related quality of life in adolescent females. 


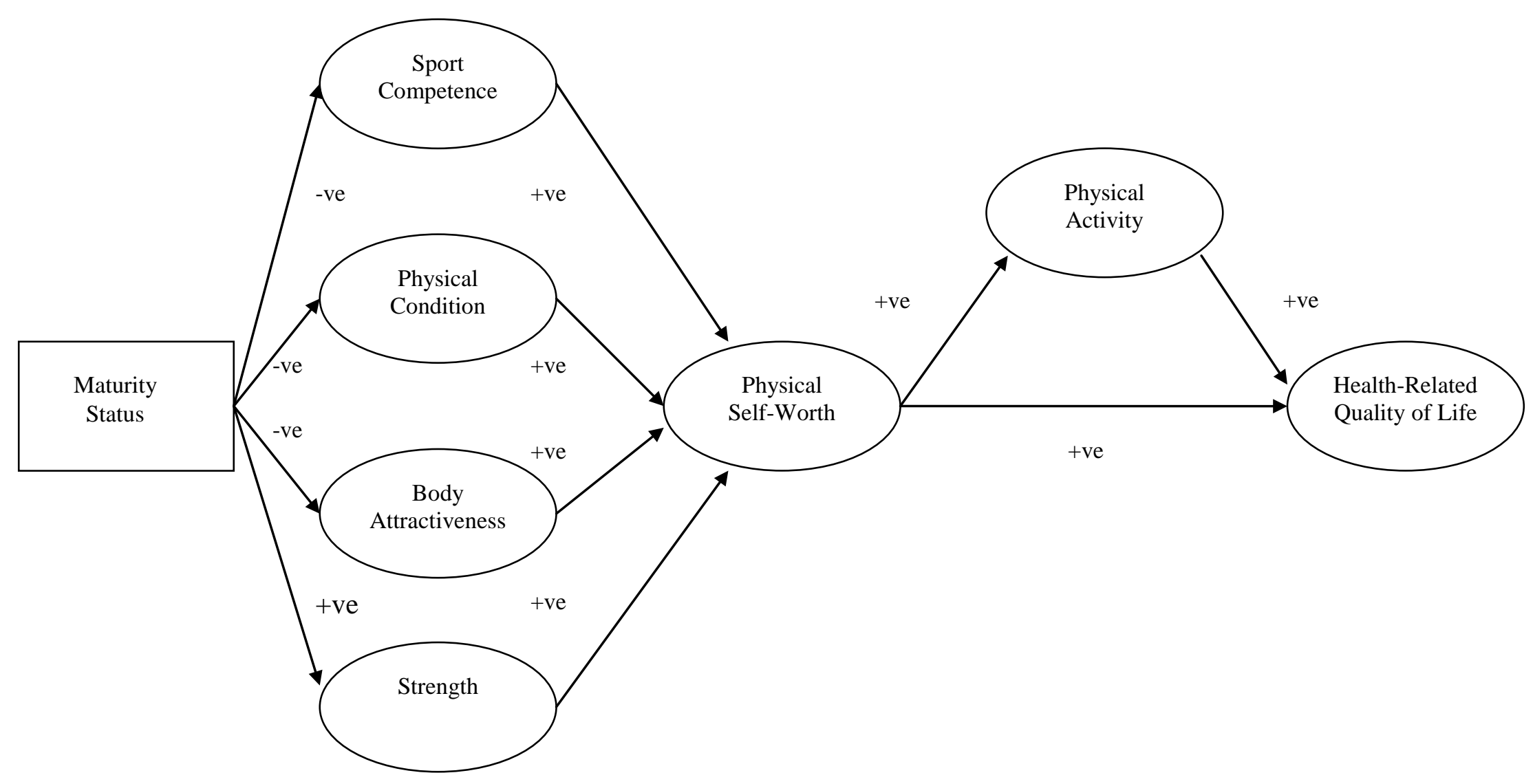


Figure 2. Mediated effects model describing relations among biological maturity status, physical self-concept, physical activity and health related quality of life in adolescent females. 


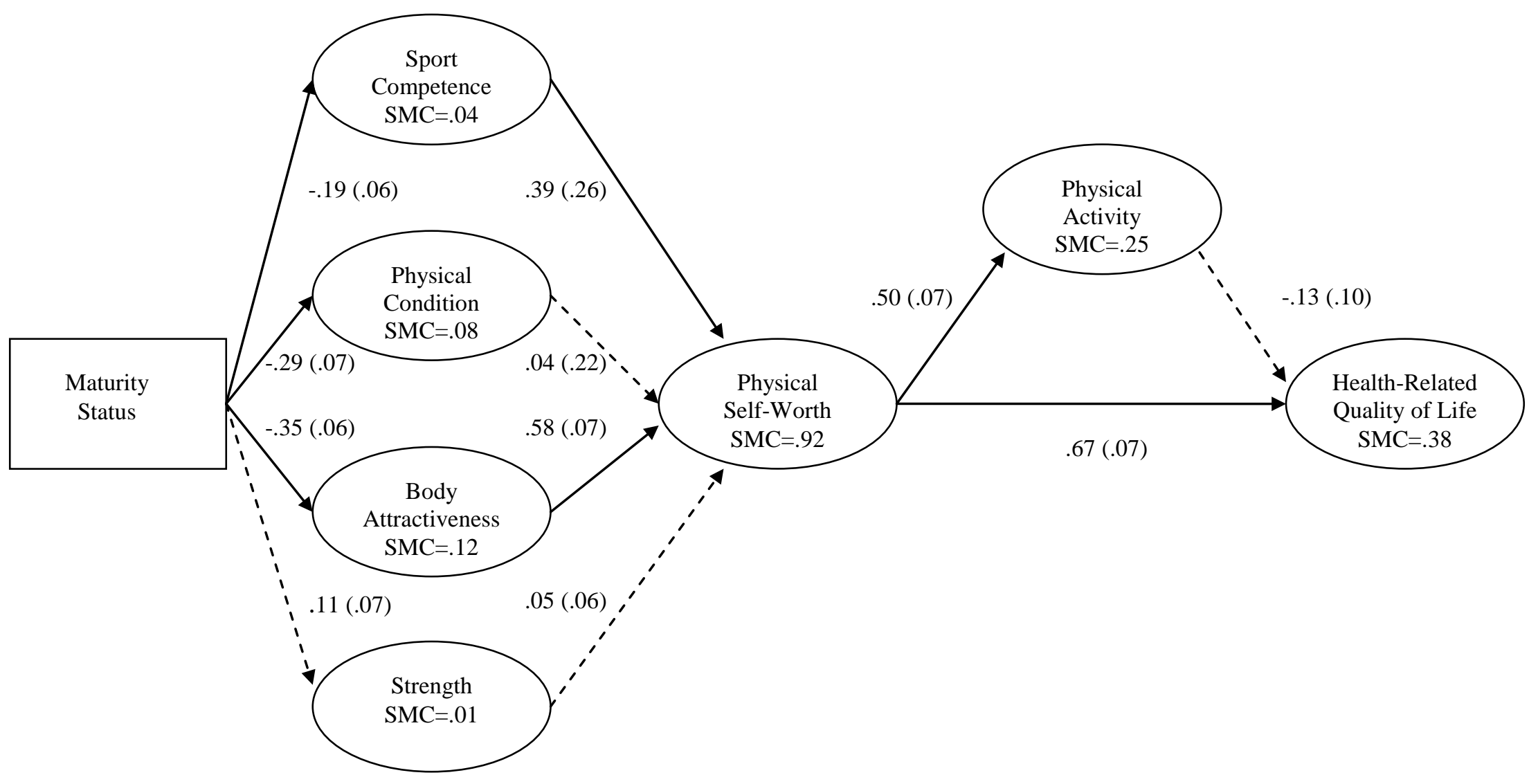

Note. All solid line parameters are significant $(\mathrm{p}<.05)$. Dashed line parameters are non-significant. Standardized Beta coefficients are presented by each parameter with standard errors in parentheses. Indirect effects were observed between maturity status and physical self-worth $(\beta=-.28$ (BBC $90 \% \mathrm{CI}=-.39,-.17), \mathrm{P}<.001)$, maturity status and physical activity $(\beta=-.14$ (BBC 90\% CI $=-.22,-.08)$, $\mathrm{P}<.001$ ), and maturity status and health related quality of life $(\beta=-.17$ (BBC 90\% CI $=-.25,-.10), \mathrm{P}<.001)$. Factors indicators are not included in the model for the purpose of making the presentation less complex. Correlations between the errors associated with the four sub-dimensions of the physical self were all significant and were as follows; sport competence \& physical condition $r=.92$; sport competence \& body attractiveness $r=.67$; sport competence \& strength $r=.66$; physical condition \& body attractiveness $r=.63$; physical condition \& strength $r=.60$; body attractiveness \& strength $r=.49$. 